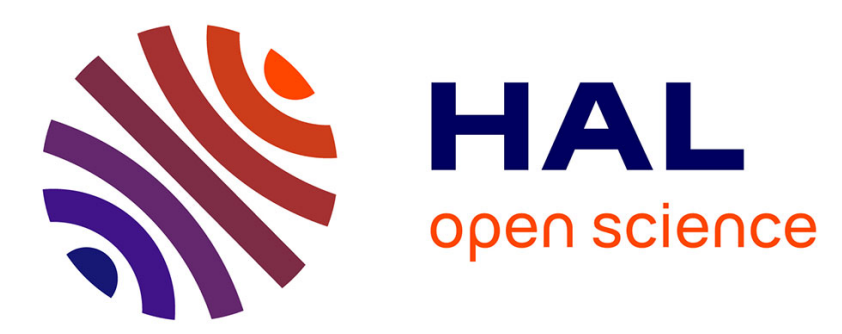

\title{
Automatic Navigation System Research for PZ60 Rice Planter
}

\author{
Liguo Wei, Xiaochao Zhang, Quan Jia, Yangchun Liu
}

\section{To cite this version:}

Liguo Wei, Xiaochao Zhang, Quan Jia, Yangchun Liu. Automatic Navigation System Research for PZ60 Rice Planter. 8th International Conference on Computer and Computing Technologies in Agriculture (CCTA), Sep 2014, Beijing, China. pp.653-661, 10.1007/978-3-319-19620-6_73 . hal01420284

\section{HAL Id: hal-01420284 \\ https://hal.inria.fr/hal-01420284}

Submitted on 20 Dec 2016

HAL is a multi-disciplinary open access archive for the deposit and dissemination of scientific research documents, whether they are published or not. The documents may come from teaching and research institutions in France or abroad, or from public or private research centers.
L'archive ouverte pluridisciplinaire HAL, est destinée au dépôt et à la diffusion de documents scientifiques de niveau recherche, publiés ou non, émanant des établissements d'enseignement et de recherche français ou étrangers, des laboratoires publics ou privés.

\section{(c)(1)}

Distributed under a Creative Commons Attribution| 4.0 International License 


\title{
Automatic Navigation System Research For PZ60 Rice Planter
}

\author{
Liguo Wei ${ }^{1,2, a}$, Xiaochao Zhang ${ }^{2, b}$, Quan Jia ${ }^{2, c}$, Yangchun Liu ${ }^{3, d}$ \\ ${ }^{1}$ Key Laboratory of Modern Agricultural Equipment, Ministry Agriculture, P.R. China, \\ Nanjing 210014, China; ${ }^{2}$ Chinese Academy of Agriculture Mechanization Sciences, Beijing \\ 100083, China; ${ }^{3}$ National Key Laboratories in areas of Soil-Plant-Machine System Technology, \\ Beijing 100083,China \\ aweilg78@126.com, bxchao2584@163.com, jiaquan301@163.com, ${ }^{\mathrm{d}}$ lyc@ @ caams.org.cn
}

\begin{abstract}
In order to satisfy the agricultural demond of rice transplanting, the transplanter work should guarantee the escapement even in straight line transplanting that is convenient for field management and harvest later. Because of variable soil conditions and hard work environment, the driver driving level and the long boring driving to follow line is a big influence to the accuracy of the rice transplant. It is easy to produce overline, leak line and cause losses in yield. Aimed at above problem, this text introduces an automatic navigation system developed on PZ60 rice transplanter based on global navigation satellite system (GNSS). The steering, transmission and transplanting control system of the rice transplanter were modified from manual control system to electrohydraulic control system using electro-hydraulic proportional valve. According to the position information of the rice transplanter acquired from GNSS receiver and vehicle sensors, the close-loop feedback control system of steering was builded. The system can accurately control rice transplanter to follow row navigating and turn around at the end of field by the self-adaptive fuzzy control method. The road and field experiment results indicated that the lateral tracking error could be kept within $100 \mathrm{~mm}$ when the speed of the rice transplant is not greater than $1.0 \mathrm{~m} / \mathrm{s}$. The control system can satisfy the requirment of rice transplanting.
\end{abstract}

Keywords: rice transplanter, global navigation satellite system, automatic navigation

\section{Introduction}

Rice is one of the most important food crop in China, the national rice planting area accounts for about $30 \%$ of the grain crop area, close to half of the total output of grain yield. Rice suitable transplanting operation time is usually 7-10 days, the rural labor resources are insufficient, the labor cost is increasing year by year. Paddy field working environment is poor, and transplanting machine take the personnel, not only energy consumption, there are also operating personnel safety hidden danger.

Automatic navigation technology is widly applied in modern agriculture and gradually becoming an important part of the agriculture engineering. At present, GNSS, machine vision and multi-sensors data fusion are the most widely applied 
automatic navigation technologies in the agricultural project. The technology of machine vision has the price advantage, but its application on the rice planter is restricted in the weak light intensity. As GNSS accuracy is continually rising and GNSS cost is continually falling, GNSS technology has a wide application on precision irrigation, fertilizer and farm robots automatic navigation ${ }^{[1-3]}$. The implementation of GNSS automatic navigation on the rice transplanter can relieve the labour intensity of the driver, extend the operating time and be conducive to the improvement of productivity and the yield of rice. The objective of this study is to develop an automatic navigation system that was developed on PZ60 rice transplanter based on RTK-GNSS navigation technology in the paper. The steering, transmission and transplanting control system of the rice transplanter were modified from manual control system to electronic control system ${ }^{[4-7]}$. The automatic navigation system integrating GNSS technology and fuzzy control strategies can control the rice transplanter trace the presetted path and achieve automatic navigation transplanting.

\section{Experiments and Methods}

It is key that the manual driving mode of farm machinery is modified to electronic control mode in order to achieve mechanical automatic navigation control and variable assignments. The PZ60 high-speed rice transplanter has four-wheel-drive,six rows, engine power 8.3 kilowatt, the escapement $300 \mathrm{~mm}$, the maximum speed of over $1.6 \mathrm{~m} / \mathrm{s}$. In order to realize automatic navigation working of the rice transplanter, the steering, HST no level shift system, braking system of the PZ60 rice transplanter were modified as shown in figure 1 .

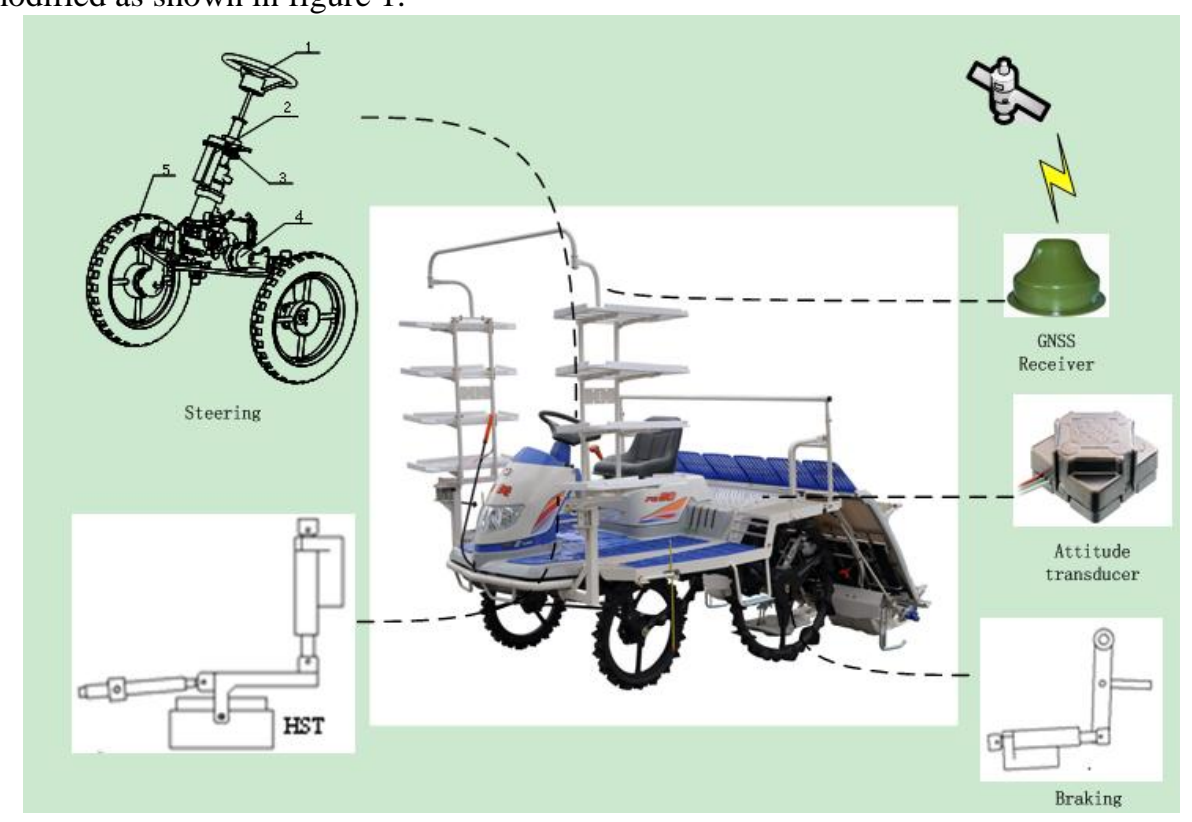

Fig.1 Diagram of rice transplanter operating mechanism 


\subsection{HST No Level Shift System}

The rice transplanter is carried out going forward and backward infinitely variable speeds through adjusting HST hydrovalve flux and flow direction. The manual operation of HST action bar was modified to driving by electric handspike. The distance of the electric handspike is $80 \mathrm{~mm}$, rating torque $75 \mathrm{~N} \cdot \mathrm{m}$, the range of work voltage $12 \sim 24 \mathrm{~V}$. The electric handspike control the hydrovalve through driving connecting plate rotation. The shift sensor fixed at the connecting plate feeds back the control position of the hydrovalve. According to testing, the electric control mechanism costs $2.3 \mathrm{~s}$ to complete HST shift system from stop to most gear forward and costs $2.1 \mathrm{~s}$ to complete HST shift system from stop to most high gear backward. It can satify the demand of the field working.

\subsection{Steering Mechanism}

The steering mechanism of PZ60 rice transplanter is composed of steering wheel, hydraulic booster and clutch gear box. The manual steering wheel was modified to driving by turning motor. Turning motor is SGMJV-04AAA61 AC servo motor made in Japan, rating power $400 \mathrm{~W}$, rating torque $M_{0}=1.27 \mathrm{~N} \cdot \mathrm{m}$, rating speed $n_{0}=3000 \mathrm{r} / \mathrm{min}$. The motor decelerated by speed reducer pass drive to hydraulic booster by clutch gear box and then turn the steering wheel by the main transmission case. The angle sensor fixed at the end of steering axle gathers steering angle. The clutch gear box was designed for automatic and manual operation switch. as shown figure2. The ininative gear joggles the tooth inlay gear. The tooth inlay can be shifted up and down through the control stick drives shifting fork. When the tooth inlay links the tooth inlay gear together, the steering mechanism is in automatic mode through motor driving. Whereas, the steering mechanism is in manual mode through the steering wheel.

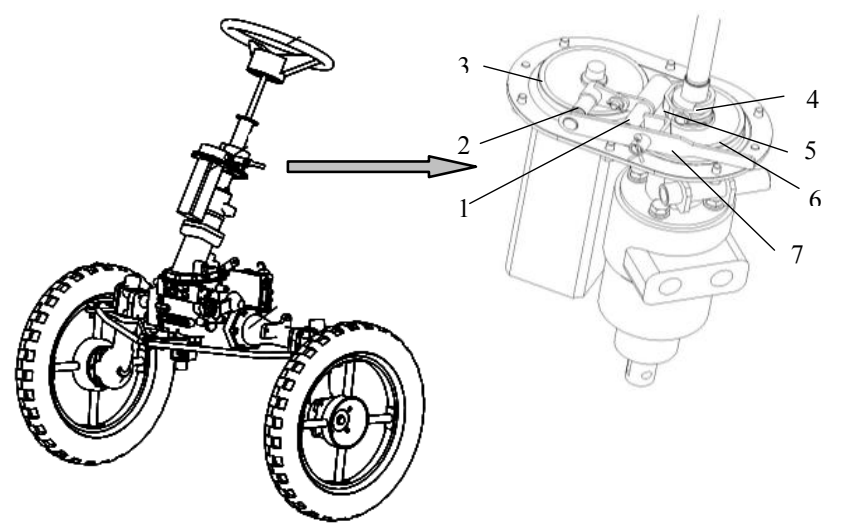

Fig.2 Structure of clutch gear box

1.Fork rotor 2.Control stick rotor 3.Ininative gear 4. Tooth inlay

5.Fork 6.Tooth inlay gear 7.Clutch control stick 
According to mensuration, driving the steering wheel needs torque $M_{z} \geq 10 \mathrm{~N} \cdot \mathrm{m}$ in normal. The retardment rate of motor retarder $i_{0}$ is $30: 1$ in the design. The transmission rate of the clutch gear box $i_{1}$ is $1: 1$. When the motor driving is by way of the clutch gear box, the output torque is:

$$
M_{1}=M_{0} \cdot i_{0} \cdot i_{1}=38.1 N \cdot m>M_{z}
$$

The retardment rate of the main gear box $i_{2}$ is $i_{2}=10.5: 1$. The rating speed of the steering output axis is:

$$
n_{1}=\frac{n_{0}}{i_{0} \cdot i_{1} \cdot i_{2}} \approx 9.5 \mathrm{r} / \mathrm{mir}
$$

The limit steering angle of the inside wheel is 45 degree. When the steering wheel turns from the left limit angle to the right limit angle, the turning angle $\theta$ of the steering output axis is 72 degree. It costs time:

$$
t=\frac{\theta}{n_{1} \times 360 / 60} \approx 1.3 \mathrm{~s}
$$

Therefore, The power and performing time of the automatic steering mechanism satisfy the need of operation.

\subsection{Automatic Navigation System}

The automatic navigation system of the rice transplanter is composed of GNSS, onboard computer, steering controller, sensors and actuators as shown in figure3.

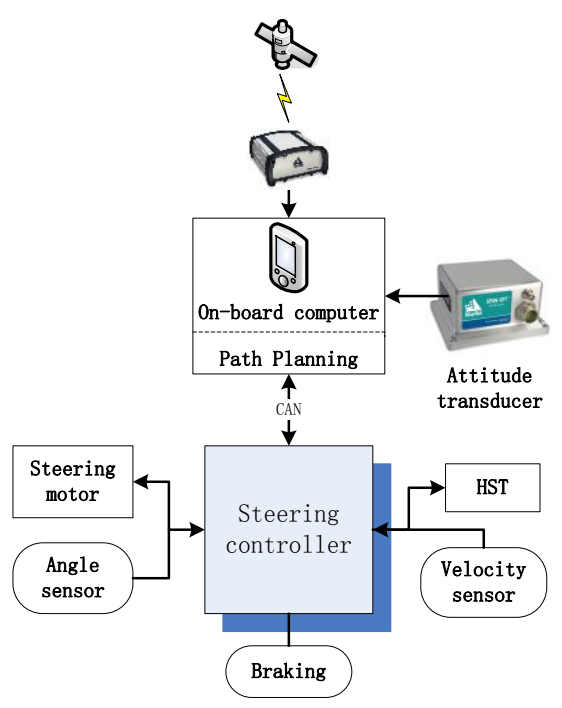

Fig.3 Automatic Navigation system 
GNSS adopts RTK locate mode that takes FlexPak6 $6^{\mathrm{TM}}$ receiver as base station, ProPak-V3 ${ }^{\mathrm{TM}}$ receiver as remotion station. Accuracy of static positioning is less than $20 \mathrm{~mm}$. The output frequency of positioning information is set for $10 \mathrm{~Hz}$. The transplanter navigation control center is a high-powered on-board computer which can receive the informations acquired by GNSS receiver and angle sensors, make intelligent behavioral decision making and output navigation information instructions. The steering controller(SC) used the AD module to acquire the attitude information of transplanter in the navigation control process which measured by angle sensor and velocity sensor, and received the navigation information instructions from on-board cumputer at the same time. SC controlled the steering motor to move accurately, adjusted the HST speed control system to make the vehicle speed within limit, made the transplanting mechanism up or down and controlled the ground-contour-following device. Data transmission between SC and on-board computer was through the serial port. Steering motor thansmitted the driving force to make the steering wheel deflexion and then change the direction timely and accurately.

Steering control is the major part of automatic navigation control to the rice transplanter. The steering motor controller used PID position control mode. Figure 4 is its control block diagram. Microcontroller used angle sensor to gather the current angle information of steering axis and send it to on-board computer as feedback information. According the horizonal deviation, yaw angle, the current angle information of steering axis and the preestablished fuzzy control rules, on-board computer made the steering control strategy and ordered microcontroller to output control signal which drove the steering motor. All of these constitute a steering closed-loop control system ${ }^{[8-10]}$.

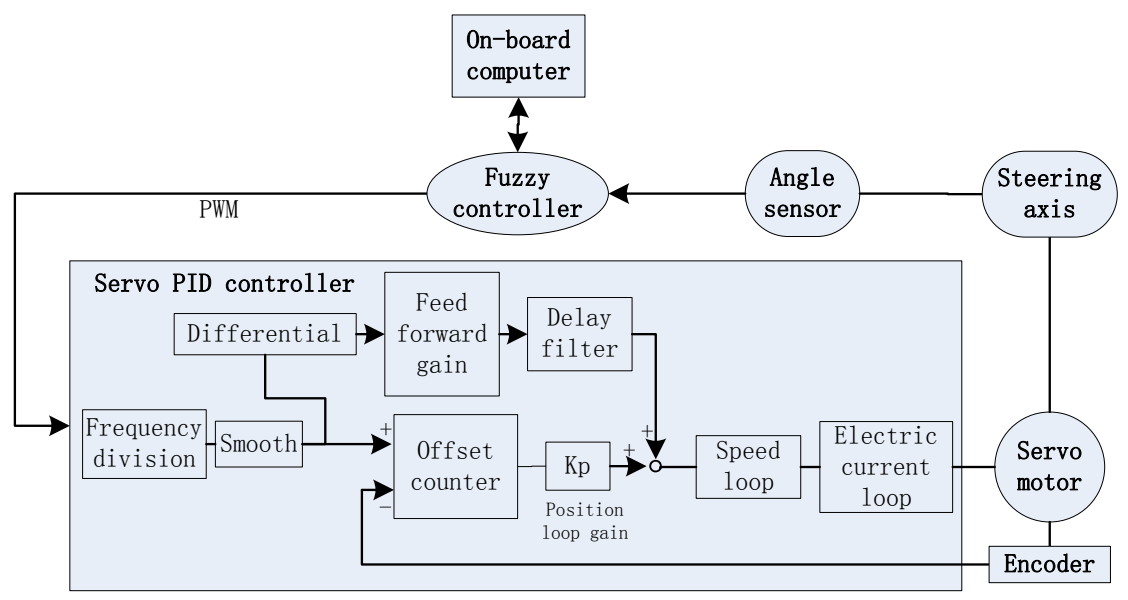

Fig.4 Diagram of steering control

\section{Results and Discussion}




\subsection{Blacktop experimentation}

In order to measure the presion of rice transplanter automatic navigation sysytem, the experimentations were done at a blank blacktop nearby beijing xiao wang village experiment station of chinese academy of agricultural mechanization sciences.

First, Two points A and B was fixed on blacktop groud, and the distance between point $\mathrm{A}$ and point $\mathrm{B}$ was longer than $80 \mathrm{~m}$. The latitude and longitude information of two points A and B was achieved using GNSS receivers, and through on-board computer path planning software to prearrange a straight path of $\mathrm{AB}$. A dropping style scriber fixed on rice transplanter was used to record the tracking of the rice transplanter on the ground. The scriber and GNSS receiver were fixed on the same centre axis of rice transplanter. After starting up the navigation control system, the rice transplanter begined automatic navigation in a definite velocity, and the scriber recorded the tracking on the ground at the same time.

After the rice transplanter completed the process of automatic navigation, a white fishing line as the navigation datum line was fixed between point $\mathrm{A}$ and point $\mathrm{B}$ on the ground. Tracking route of the rice transplanter recorded by scriber compared with the navigation datum line, and used meter ruler to measure the deviation as shown in figure 5. The experiment data is shown in table 1. According to the experiment testing, the rice transplanter automatic navigation error is not greater than $100 \mathrm{~mm}$ when the rice transplanter is not greater than $3.6 \mathrm{~km} / \mathrm{h}$.

Table 1. Experiment data

\begin{tabular}{|c|c|c|c|}
\hline $\begin{array}{c}\text { Segment } \\
\text { number }\end{array}$ & $\begin{array}{c}\text { Sampling } \\
\text { point } \\
\text { number }\end{array}$ & $\begin{array}{l}\text { Sampling } \\
\text { point } \\
\text { deviation } \\
(\mathrm{mm}) \\
\end{array}$ & $\begin{array}{l}\text { Speed } \\
(\mathrm{km} / \mathrm{h})\end{array}$ \\
\hline \multirow{5}{*}{ S1 } & 1 & 42 & \multirow{5}{*}{2.0} \\
\hline & 2 & 28 & \\
\hline & 3 & 20 & \\
\hline & 4 & 4 & \\
\hline & 5 & 45 & \\
\hline \multirow{5}{*}{ S2 } & 6 & 51 & \multirow{5}{*}{2.5} \\
\hline & 7 & 64 & \\
\hline & 8 & 60 & \\
\hline & 9 & 82 & \\
\hline & 10 & 80 & \\
\hline \multirow{5}{*}{ S3 } & 11 & 75 & \multirow{5}{*}{3.2} \\
\hline & 12 & 87 & \\
\hline & 13 & 13 & \\
\hline & 14 & 40 & \\
\hline & 15 & 21 & \\
\hline
\end{tabular}




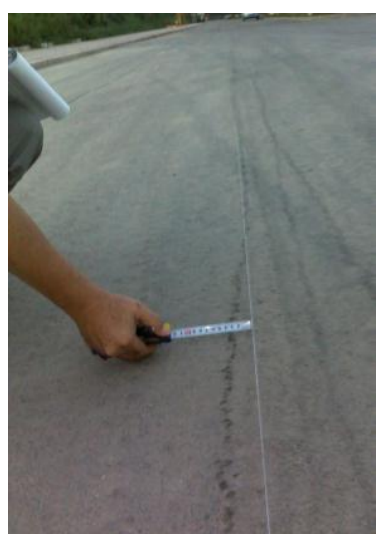

Fig.5 Deviation measurement

\subsection{Paddy field experimentation}

The paddy field experimentations were promoted in MiYun agricultural mechanization demonstration centre. The range of mud depth in the paddy field was 200 300 mm. The paddy field expermentations were as shown in figure 6 . The velocity of the rice transplanter was $0.7 \mathrm{~m} / \mathrm{s}$. The tracking of the rice transplanter was recorded by GNSS receiver as shown in figure 7, real line for prearranged route, dashed line for following route. It can be seen from figure 5, following route essentially coincides with prearranged route in addition to following error at the end of the field. A large tracking errors appears in the joint of line following and turning at the end of the field, except with the maxiam mechanism steering angle correlation and control strategy also needs to be further improved.

According to measurement, the following line error of the rice transplanter is not greater than $100 \mathrm{~mm}$ and the automatic navigation system has good controlling precision and stability. It can satisfy the agricultural demand of rice transplanting

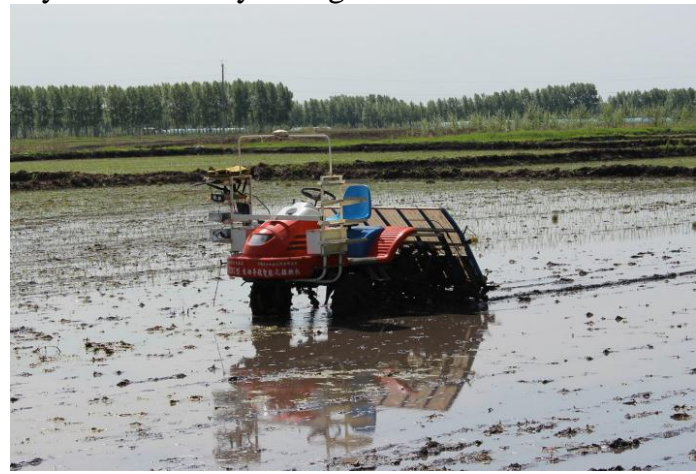

Fig.6 Paddy field experimentations 


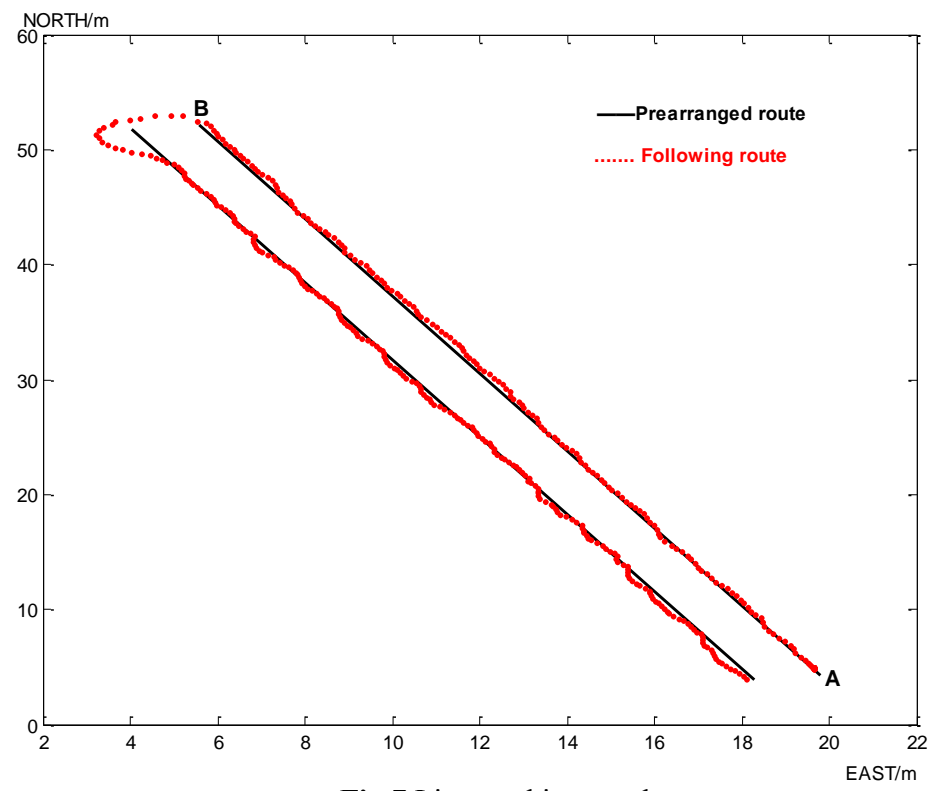

Fig.7 Line tracking result

\section{Conclusions}

(1) In order to study agricultural machinery navigation and variable working, the steering, transmission and transplanting control system of the rice transplanter were modified from manual control system to electronic control system drived by servo motors. The navigation controller designed based on GPS technology realizes the rice transplanter automatic navigation working.

(2)The tracking error of automatic navigation system is not greater than $10 \mathrm{~cm}$ when the rice transplanter velocity is not greater than $1 \mathrm{~m} / \mathrm{s}$ in paddy field experimentations. It can satisfy the precision demand of rice transplanter automatic following line.

(3)Rice transplanter structure is complex, more joysticks need operation, the full realization of the unmanned is difficult. The autopilot system is transformation on the basis of the original, the steering system reform is relatively easy, and the transformation of the shift, clutch, throttle lever is more difficult. Paddy field working environment is poor, odds mud depth and wheel slipping impact on the effect of automatic navigation control. So, how to advance the performance of automatic navigation system from mechanical and control strategies that need more experimentation research. 


\section{Acknowledgment}

Funds for this research was provided by the National Science and Technology Plan Projects (2013BAD28Q01). This study is based on work supported by the key laboratory modern agricultural equipment ministry of agriculture, P.R. China.

\section{References}

1. John F. Reid, Qin Zhang, Noboru Noguchi, et a1. Agricultural automatic guidance research inNorth America. Computers and electronics in Agriculture, 25(2000): 155-167.

2. Li Jianping, Lin Miaoling. Research progress of antomatic guidance technologies applied in agricultural engineering[J]. Transaction of the Chinese Society of Agricultural Engineering, 2006,22(9):232-236.

3. Zhang Zhigang, Luo Xiwen, Zhou Zhiyan, et al. Design of GPS Navigation control system for rice transplanter[J]. Transactions of the Chinese Society for Agricultural Machinery, 2006,37(7):95-97.

4. Yoshisada Nagasaka, Naonobu Umeda, Yutaka Kanetai, et al. Autonomous guidance for rice transplanting using global positioning and gyroscopes[J]. Computers ans electronics in Agriculture, 2004,43:223-234.

5. Q. Zhang, S. Cetinkunt, T. Hwang, et a1. Use of adaptive control algorithms for automatic calibration of electrohydraulic actuator control. Applied Engineering in Agriculture, Vol 17(3): 259-265.

6. Hu Lian, Luo Xiwen, Zhao Zuoxi, et al. Design of electronic control device and control algorithm for rice transplanter[J]. Transaction of the Chinese Society of Agricultural Engineering, 2009,25(4):118-122.

7. Zhang Q. A generic fuzzy electrohydraulic steering controller for off-road vehicles[J]. Automobile Engineering, 2003,217:791-799.

8. Sun Heng, Chen Zuomo. Machines and mechanisms theory (Sixth Edition) [M].Beijing: Higher Education Press, 2001.

9. Hu Shousong. Automatic control theory(Fourth Edition)[M]. Beijing: Science Press, 2000.

10. Chen W C, Gao G W, Wang J, et al. The Study of the MEMS Gyro Zero Drift Signal Based on the Adaptive Kalman Filter[J]. Key Engineering Materials, 2012, 500: 635-639. 